\title{
Development and characterization in vitro of a catalase-based biosensor for hydrogen peroxide monitoring
}

\author{
K.B. O’Brien ${ }^{\mathrm{a}, \mathrm{b}}$, S.J. Killoran ${ }^{\mathrm{b}}$, R.D. O’Neill ${ }^{\mathrm{b}}$, J.P. Lowry ${ }^{\mathrm{a}, *}$ \\ a Sensors Development Unit, BioAnalytics Laboratory, Department of Chemistry, National University of Ireland, Maynooth, Co, Kildare, Ireland \\ ${ }^{\mathrm{b}}$ UCD School of Chemistry and Chemical Biology, University College Dublin, Belfield, Dublin 4, Ireland
}

Received 15 August 2006; received in revised form 20 November 2006; accepted 12 December 2006

Available online 27 December 2006

\begin{abstract}
There is increasing evidence that hydrogen peroxide $\left(\mathrm{H}_{2} \mathrm{O}_{2}\right)$ may act as a neuromodulator in the brain, as well as contributing to neurodegeneration in diseased states, such as Parkinson's disease. The ability to monitor changes in endogenous $\mathrm{H}_{2} \mathrm{O}_{2}$ in vivo with high temporal resolution is essential in order to further elucidate the roles of $\mathrm{H}_{2} \mathrm{O}_{2}$ in the central nervous system. Here, we describe the in vitro characterization of an implantable catalase-based $\mathrm{H}_{2} \mathrm{O}_{2}$ biosensor. The biosensor comprises two amperometric electrodes, one with catalase immobilized on the surface and one without enzyme (blank). The analytical signal is then the difference between the two electrodes. $\mathrm{The}_{2} \mathrm{H}_{2}$ sensitivity of various designs was compared, and ranged from 0 to $56 \pm 4 \mathrm{~mA} \mathrm{~cm}^{-2} \mathrm{M}^{-1}$. The most successful design incorporated a Nafion ${ }^{\circledR}$ layer followed by a poly- $O$-phenylenediamine (PPD) polymer layer. Catalase was adsorbed onto the PPD layer and then cross-linked with glutaraldehyde. The ability of the biosensors to exclude interference from ascorbic acid, and other interference species found in vivo, was also tested. A variety of the catalase-based biosensor designs described here show promise for in vivo monitoring of endogenous $\mathrm{H}_{2} \mathrm{O}_{2}$ in the brain.
\end{abstract}

(C) 2007 Elsevier B.V. All rights reserved.

Keywords: Catalase; Hydrogen peroxide; Brain; $\mathrm{Nafion}^{\circledR}$; Poly (o-phenylenediamine); Reactive oxygen species (ROS)

\section{Introduction}

Hydrogen peroxide $\left(\mathrm{H}_{2} \mathrm{O}_{2}\right)$ and other reactive oxygen species can cause oxidative damage when present at high concentrations in the brain, and have been linked to neurodegenerative diseases such as Parkinson's disease (Simonian and Coyle, 1996). However, recent evidence has shown that reactive oxygen species can also act as signaling molecules (Stone and Yang, 2006). For example, in striatal and midbrain slices, exogenous $\mathrm{H}_{2} \mathrm{O}_{2}$ inhibits dopamine release by a mechanism involving $\mathrm{K}_{\mathrm{ATP}}$ channels (Avshalumov et al., 2005; Avshalumov and Rice, 2003). Furthermore, endogenous $\mathrm{H}_{2} \mathrm{O}_{2}$ concentrations can be influenced by neuronal activity as activation of AMPA receptors by glutamate can result in endogenous $\mathrm{H}_{2} \mathrm{O}_{2}$ generation (Avshalumov et al., 2003).

Most of the evidence reported thus far for the action of $\mathrm{H}_{2} \mathrm{O}_{2}$ as a neuromodulator has been indirect and obtained from brain slice preparations. $\mathrm{H}_{2} \mathrm{O}_{2}$ concentrations are usually altered

\footnotetext{
* Corresponding author. Tel.: +3531708 4639; fax: +3531 1083815 .

E-mail address: john.lowry@ nuim.ie (J.P. Lowry).
}

by applying exogenous $\mathrm{H}_{2} \mathrm{O}_{2}$ at high concentrations $(\sim 1 \mathrm{mM})$ or endogenous $\mathrm{H}_{2} \mathrm{O}_{2}$ levels are increased by inhibiting catalase, an enzyme that degrades $\mathrm{H}_{2} \mathrm{O}_{2}$ in the brain (Avshalumov et al., 2000, 2003; Avshalumov and Rice, 2002; Chen et al., 2001, 2002). The effect of altering the $\mathrm{H}_{2} \mathrm{O}_{2}$ concentration on dopamine release or other parameters has been studied in this way. However, little is known about the endogenous concentration of $\mathrm{H}_{2} \mathrm{O}_{2}$ and how it changes with neuronal activity.

Intracellular $\mathrm{H}_{2} \mathrm{O}_{2}$ in isolated neurons has been measured by fluorescent imaging but this approach allows only relative changes in $\mathrm{H}_{2} \mathrm{O}_{2}$ to be measured as the absolute concentration of $\mathrm{H}_{2} \mathrm{O}_{2}$ cannot be determined. Also, as the fluorescent reaction is irreversible, subsequent decreases in $\mathrm{H}_{2} \mathrm{O}_{2}$ cannot be measured (Avshalumov et al., 2005; Bao et al., 2005). Microdialysis has been used to measure endogenous $\mathrm{H}_{2} \mathrm{O}_{2}$ in vivo. Measurements by microdialysis estimate basal levels of hydrogen peroxide at 25-50 $\mathrm{MM}$ in rats (Hyslop et al., 1995; Lei et al., 1997a,b) and 1-2 $\mu \mathrm{M}$ in gerbils (Lei et al., 1997a,b, 1998), although $\mathrm{H}_{2} \mathrm{O}_{2}$ concentrations may be elevated in these studies due to damage caused by insertion of the microdialysis probe into the brain. Also, due to sample volume constraints, dialysates were collected only once every $10-20 \mathrm{~min}$. This temporal resolution is 
insufficient for measuring rapid changes in $\mathrm{H}_{2} \mathrm{O}_{2}$ that would likely be associated with $\mathrm{H}_{2} \mathrm{O}_{2}$ acting as a neuromodulator.

Improved temporal resolution can be achieved using biosensors for monitoring $\mathrm{H}_{2} \mathrm{O}_{2}$ (Ferapontova et al., 2001; Schuvailo et al., 2005; Wang et al., 2003). While several biosensors have been developed for monitoring $\mathrm{H}_{2} \mathrm{O}_{2}$ in bulk solution, only two have been used for measurements of $\mathrm{H}_{2} \mathrm{O}_{2}$ in ECF (Kulagina and Michael, 2003; Mao et al., 2002) and only one of these is implantable (Kulagina and Michael, 2003). The implantable biosensor uses the enzyme horseradish peroxidase and relies on a cross-linked redox polymer to act as a mediator, and Nafion ${ }^{\circledR}$ and ascorbate oxidase to decrease ascorbic acid (AA) interference in the $\mathrm{H}_{2} \mathrm{O}_{2}$ signal. Here, we describe a simpler, mediatorless hydrogen peroxide biosensor based on the enzyme catalase, where Nafion ${ }^{\circledR}$ and poly-phenylenediamine (PPD) layers block interference from endogenous reducing agents, such as AA.

\section{Materials and methods}

\subsection{Chemicals}

All chemicals used were of analytical reagent grade or higher quality and purchased from Sigma-Aldrich Chemicals. Nafion ${ }^{\circledR}$ was obtained as a 5\% solution in alcohol from Sigma. Phosphate buffered saline (PBS), pH 7.4 was $150 \mathrm{mM} \mathrm{NaCl}, 40 \mathrm{mM} \mathrm{NaOH}$ and $40 \mathrm{mM} \mathrm{NaH} 2 \mathrm{PO}_{4}$. All solutions were prepared in deionized water.

\subsection{Electrode preparation}

Bare cylinder electrodes were made from Teflon-insulated platinum/iridium ( $\mathrm{Pt} / \mathrm{Ir}, 90 \% / 10 \%)$ wire (125 $\mu \mathrm{m}$ bare diameter, $25 \mu \mathrm{m}$ coated diameter, Advent Research Materials, Suffolk, $\mathrm{UK})$. The Pt/Ir wire, represented hereafter as Pt, was then soldered into a gold electrical contact (Fine Science Tools, Linton, UK). $2 \mathrm{~mm}$ cylinders were prepared by carefully removing the Teflon coating from the opposite end of the wire. The bare Pt cylinder electrodes were then modified using various protocols. Each electrode used in these studies was freshly prepared by removing the Teflon from the coated wire just before use, obviating the need for surface cleaning procedures, which can, in some cases, decrease the variability of observed electrochemical responses (Saraceno and Ewing, 1988).

\subsection{Electrode modification}

The following modifications were made to the electrodes in different combinations. Phosphatidyl-ethanolamine (PEA, $100 \mathrm{mg} / \mathrm{mL}$ in chloroform) was applied by dipping electrodes quickly $(\sim 0.5 \mathrm{~s})$ once and air-drying for 5 min. Nafion ${ }^{\circledR}(\mathrm{Naf})$ was applied by dipping $(\sim 0.5 \mathrm{~s})$ five times; electrodes were air dried for $5 \mathrm{~min}$ between each dip. To adsorb catalase (CAT) onto the electrode surface, electrodes were left for $5 \mathrm{~min}$ in $25 \mathrm{mg} / \mathrm{mL}$ CAT in PBS for $5 \mathrm{~min}$ and then air-dried for $5 \mathrm{~min}$. The electrodes were then dipped $(\sim 0.5 \mathrm{~s})$ into the CAT solution an additional four times, with 5 min allowed for air-drying between each dip. Poly (o-phenylenediamine) (PPD) was formed by elec- tropolymerisation of $o$-phenylenediamine (o-PD) as described previously (Dixon et al., 2002). Styrene (Sty, 99\%), cellulose acetate (CA, 1\%, w/w in acetone), glutaraldehyde (GA, 1\%), glutaraldehyde/bovine serum albumin (GA-BSA, $10 \mathrm{mg} / \mathrm{mL}$ ) were applied by dipping electrodes $(\sim 0.5 \mathrm{~s})$ once and air-drying for $5 \mathrm{~min}$.

\subsection{Calibrations}

The working electrodes were placed in the glass cell and the potential $(+700 \mathrm{mV})$ was applied. Once the current response of the working electrodes had reached a stable baseline ( $\sim 60 \mathrm{~min})$, calibrations were performed. Hydrogen peroxide $\left(\mathrm{H}_{2} \mathrm{O}_{2}\right)$ calibrations $(0,2,5,10,20,50$ and $100 \mu \mathrm{M})$ were performed on all electrodes before and after modification, in air-saturated PBS. Ascorbic acid (AA) calibrations (0, 200, 400, 600, 800 and $1000 \mu \mathrm{M}$ ) were performed on all electrodes after modification, in nitrogen-saturated PBS. $\mathrm{H}_{2} \mathrm{O}_{2}$ calibrations (same concentrations as above) were also performed on modified electrodes in the presence of AA $(400 \mu \mathrm{M})$. All experiments were carried out at room temperature. For all calibrations, injections were made every $3 \mathrm{~min}$. Solutions were stirred briefly (20 s) after the addition of each standard aliquot. The current response for each concentration was measured immediately before the next injection was made (i.e. $3 \mathrm{~min}$ after injection).

\subsection{Interference characterization}

Calibrations were performed with the following interferents in nitrogen-saturated PBS: L-tyrosine $(1-100 \mu \mathrm{M})$,

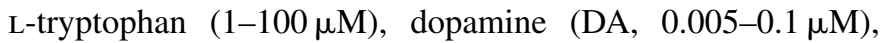
L-cysteine $\quad(5-100 \mu \mathrm{M}), \quad 3,4$-dihydroxyphenylacetic acid (DOPAC, 5-40 $\mu \mathrm{M}$ ), 5-hydroxyindole acetic acid (5-HIAA, $10-100 \mu \mathrm{M})$ and glutathione $(5-50 \mu \mathrm{M})$. Single injections of 5-hydroxytyramine (5-HT, $0.02 \mu \mathrm{M}$ ), homovanillic acid (HVA, $20 \mu \mathrm{M}$ ) and uric acid (UA, $100 \mu \mathrm{M}$ ) were made.

\subsection{Instrumentation and software}

All experiments were performed in a standard electrochemical cell, which was constructed in house. A saturated calomel electrode (SCE) was used as the reference electrode and a large $\mathrm{Pt}$ wire served as the auxiliary electrode. Constant potential amperometry was performed at $+700 \mathrm{mV}$ using Chart (V5.2) software (AD Instruments Ltd., Oxford, UK), and a low-noise potentiostat (ACM Instruments, Cumbria, LA, UK). The potentiostat has 4-channels so that four working electrodes were simultaneously tested (two CAT and two BLANK electrodes). A Powerlab/400 interface system (AD Instruments Ltd.) was used to acquire data onto a PC.

\subsection{Data analysis}

When implanted in vivo, the current measured at both the CAT $\left(I_{\mathrm{CAT}}\right)$ and blank $\left(I_{\mathrm{BLANK}}\right)$ electrodes will arise from interference species $\left(I_{\mathrm{INT}}\right.$ and $I_{\text {INT }}^{\prime}$, respectively) present in the extracellular 
fluid (ECF), as well as endogenous hydrogen peroxide $\left(I_{\mathrm{HP}}\right)$ :

$I_{\mathrm{BLANK}}=I_{\mathrm{INT}}+I_{\mathrm{HP}}$

$I_{\mathrm{CAT}}=I_{\mathrm{INT}}^{\prime}+C_{\mathrm{HP}} I_{\mathrm{HP}}$

where $C_{\mathrm{HP}}$ is the fraction of $\mathrm{H}_{2} \mathrm{O}_{2}$ not degraded by the catalase before reaching the electrode surface, and is ideally zero. If the interference current at both electrodes is the same $\left(I_{\mathrm{INT}}=I_{\mathrm{INT}}\right.$, and determined by calibration), then subtraction of the CAT electrode current from the blank electrode current will yield a difference $(\Delta I)$ that depends only on the hydrogen peroxide concentration,

$\Delta I=I_{\mathrm{BLANK}}-I_{\mathrm{CAT}}=\left(1-C_{\mathrm{HP}}\right) I_{\mathrm{HP}}$

If $I_{\mathrm{INT}} \neq I_{\mathrm{INT}}^{\prime}$ and $I_{\mathrm{INT}}^{\prime}=C_{\mathrm{INT}} I_{\mathrm{INT}}$, then

$\Delta I=\left(1-C_{\mathrm{INT}}\right) I_{\mathrm{INT}}+\left(1-C_{\mathrm{HP}}\right) I_{\mathrm{HP}}$

where $C_{\mathrm{INT}}$ is the interference proportionality constant between the CAT and blank electrodes. The value of $C_{\mathrm{INT}}$ is ideally unity, but its importance diminishes as the value of $I_{\text {INT }}$ itself decreases relative to $I_{\mathrm{HP}}$, with more effective interference rejection of the permselective layer design. The $\mathrm{H}_{2} \mathrm{O}_{2}$ sensitivity of each biosensor design was calculated by subtracting the CAT electrode current $\left(I_{\mathrm{CAT}}\right)$ from the blank electrode current ( $\left.I_{\mathrm{BLANK}}\right)$. Electrodes were paired based on their bare $\mathrm{Pt}_{2} \mathrm{O}_{2}$ sensitivity, before modification of the electrode surface. All values reported are the average \pm S.E.M. (standard error mean), with $n$ being the number of electrodes or electrode pairs. Values of $p$ quoted are for paired or unpaired Student's $t$-tests, where appropriate, calculated using Microsoft Excel.

\section{Results and discussion}

Enzyme-based amperometric biosensors that incorporate PPD (poly-o-phenylenediamine) as the permselective layer have been described for a variety of analytes, especially for in vivo monitoring (O'Neill et al., 1998; Wilson and Gifford, 2005). PPD displays a useful combination of high permeability to enzyme-generated $\mathrm{H}_{2} \mathrm{O}_{2}$ (Lowry et al., 1994; Murphy, 1998; Hamdi et al., 2005) and effective rejection of interference species, such as ascorbic acid (Sasso et al., 1990; Craig and O'Neill, 2003; McMahon et al., 2004). Recently, we reported that enzyme-free PPD-modified Pt sensors (Pt/PPD), implanted in the brain, responded to stimuli with a time course that suggested endogenous $\mathrm{H}_{2} \mathrm{O}_{2}$ produced by neuronal activity might be responsible for the signal (Lowry et al., 2001). However, other electroactive molecules present in brain extracellular fluid (ECF) might also produce rapid transients at PPD-modified surfaces (Friedemann et al., 1996). In the present study, we investigate the incorporation of an $\mathrm{H}_{2} \mathrm{O}_{2}$-specific component into the sensor (catalase) and variations of this basic design to maximize the catalase activity (small $C_{\mathrm{HP}}$, Eq. (4)) and optimize further the interference rejecting characteristics $\left(C_{\mathrm{INT}}\right.$ close to unity, Eq. (4)) to produce a sensor capable of detecting micromolar concentrations of $\mathrm{H}_{2} \mathrm{O}_{2}$ in brain ECF. Other factors that are important for implantable biosensors, including stability and susceptibility to protein/lipid fouling, will be the focus of further work. However, previous work has shown that biosensors incorporating PPD are stable both in vitro and in vivo (Lowry et al., 1994, 1998a,b; Lowry and O’Neill, 1994).

Nine biosensor designs were fabricated and characterized in vitro. The composition of each design is listed in Table 1. Blank electrodes for each design were fabricated in the same manner, except that the CAT layer was omitted. Details of how each layer was applied are given in Section 2.2.

\subsection{Hydrogen peroxide sensitivity}

At $+700 \mathrm{mV}$ versus $\mathrm{SCE}, \mathrm{H}_{2} \mathrm{O}_{2}$ is oxidized on Pt surfaces at a diffusion-controlled rate, resulting in a current response that is linearly dependent on concentration (Lowry et al., 1994). The catalase-based $\mathrm{H}_{2} \mathrm{O}_{2}$ biosensor described here consists of a pair of Pt electrodes, one with catalase immobilized on the electrode (CAT electrode) and one without catalase (blank electrode). When used in vivo, the two electrodes will be implanted in close proximity and the current from each will be simultaneously recorded. Since catalase is an enzyme that degrades $\mathrm{H}_{2} \mathrm{O}_{2}$ to water and oxygen, the $\mathrm{H}_{2} \mathrm{O}_{2}$ response of the CAT electrode is lower than the blank electrode (Fig. 1A). Thus, the $\mathrm{H}_{2} \mathrm{O}_{2}$ response of these novel catalase biosensors is the difference between the blank electrode (without enzyme) and the corresponding CAT electrode (Fig. 1B).

Designs 1-3 (Table 1) were all based on a combination of PEA, PEI, PPD-BSA and CAT layers. The lipid PEA was included because of its ability to block interference when combined with PPD (McAteer and O’Neill, 1996; Ryan et al., 1997;

Table 1

Hydrogen peroxide sensitivity of the catalase-based hydrogen peroxide biosensors

\begin{tabular}{|c|c|c|}
\hline Design number & Composition $(n)$ & $\mathrm{H}_{2} \mathrm{O}_{2}$ sensitivity ( $\mathrm{nA} / \mu \mathrm{M} \pm$ S.E.M.) \\
\hline 1 & Pt/PEA/CAT/PPD-BSA (6) & $0.42 \pm 0.11$ \\
\hline 2 & Pt/PEA/PEI/CAT/PPD-BSA (4) & $0.32 \pm 0.5$ \\
\hline 3 & Pt/PEA/PPD-BSA/CAT/GA (3) & $0.67 \pm 0.23$ \\
\hline 4 & $\mathrm{Pt} / \mathrm{CAT} / \mathrm{Naf}(4)$ & $0.31 \pm 0.04$ \\
\hline 5 & Pt/CAT/Naf/PPD-BSA (3) & $-0.07 \pm 0.04$ \\
\hline 6 & $\mathrm{Pt} / \mathrm{Naf} / \mathrm{PPD} / \mathrm{CAT} / \mathrm{GA}(8)$ & $0.45 \pm 0.03$ \\
\hline 7 & Pt/Naf/PPD/CAT/GA-BSA (4) & $0.12 \pm 0.02$ \\
\hline 8 & $\mathrm{Pt} / \mathrm{Naf} / \mathrm{PPD} / \mathrm{CAT} / \mathrm{CA}(4)$ & $0.09 \pm 0.03$ \\
\hline 9 & Pt/Naf/PPD/CAT/Sty (3) & $0.16 \pm 0.04$ \\
\hline
\end{tabular}

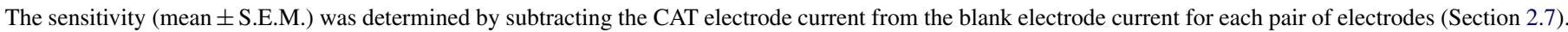



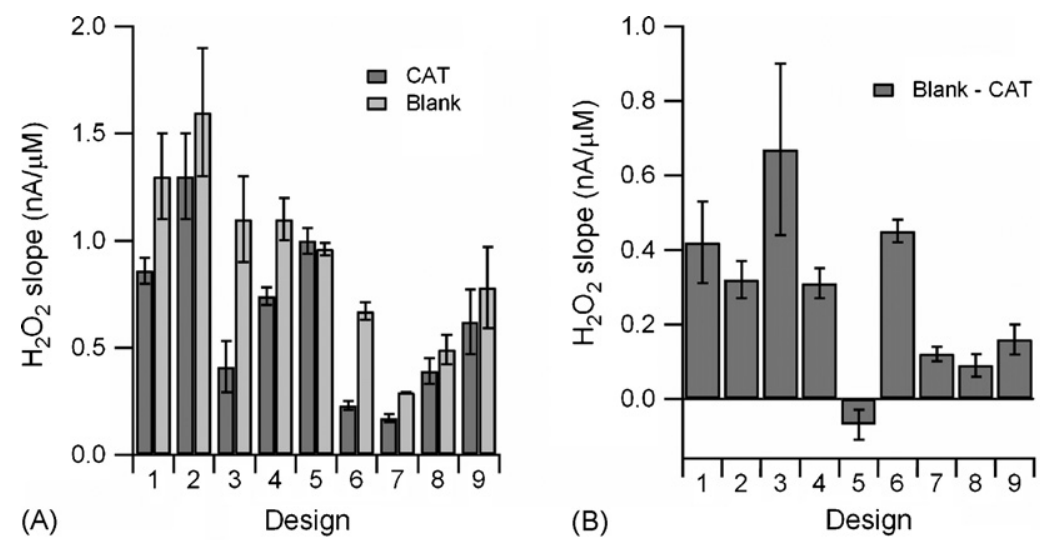

Fig. 1. Comparison of $\mathrm{H}_{2} \mathrm{O}_{2}$ sensitivity for electrode designs 1-9. $\mathrm{H}_{2} \mathrm{O}_{2}$ calibrations $(0-100 \mu \mathrm{M})$ were performed as described in Section 2 and the slope of the linear response determined for each electrode. (A) The average sensitivity (mean \pm S.E.M.) of the CAT and blank electrodes for each design. (B) The sensitivity (mean \pm S.E.M.) of the biosensor couple was determined by subtracting the CAT electrode current from the blank electrode current for each pair of electrodes.

Wang and $\mathrm{Wu}, 1993)$, and the polycation PEI can increase the activity of some adsorbed enzymes (McMahon et al., 2006; Varma et al., 2006). The $\mathrm{H}_{2} \mathrm{O}_{2}$ sensitivity ( $\Delta I$ in Eq. (4), nA/ $\mu \mathrm{M}$ ) of all three designs was high (design 1, $0.42 \pm 0.11, n=6$; design $2,0.32 \pm 0.05, n=4$; design $3,0.67 \pm 0.23, n=3$ ) indicating that CAT remains active when adsorbed on the electrode surface and immobilized with PPD-BSA or glutaraldehyde (GA). Placing the CAT layer over the PEA and PPD-BSA layers (design 3) resulted in higher $\mathrm{H}_{2} \mathrm{O}_{2}$ sensitivities than placing the CAT layer under PPD-BSA (designs 1 and 2) but the difference was not statistically significant $\left(p=0.3\right.$, unpaired $t$-test). The $\mathrm{H}_{2} \mathrm{O}_{2}$ response for the blank electrodes of designs 1 and 3 were similar (Fig. 1A) indicating comparable $\mathrm{H}_{2} \mathrm{O}_{2}$ permeability for both designs. Thus, the higher sensitivity was due to greater CAT activity when the enzyme was immobilized by GA instead of PPD.

Design 2 incorporated the polycation PEI. PEI has been used to stabilize enzymes, such as glutamate oxidase (Belay et al., 1999) and has been used in a glutamate biosensor to reduce repulsion between substrate and enzyme (McMahon et al., 2006). Here, inclusion of a PEI layer did not result in an enhancement of catalase activity (design 1 versus 2 ). In the case of the glutamate biosensor (McMahon et al., 2006), both the substrate and the enzyme are negatively charged and PEI acts to reduce electrostatic repulsion between the enzyme and substrate. For the hydrogen peroxide biosensor, the catalase enzyme is negatively charged at $\mathrm{pH} 7.4(\mathrm{pI}=5.4)$ but the substrate is neutral. Hence, PEI does not enhance substrate-enzyme interactions, nor did it appear to stabilize the enzyme resulting in higher activity.

Designs 4-9 all included Nafion ${ }^{\circledR}$, a perfluorinated polymer that has been used previously in sensors to block AA interference (Brown and Lowry, 2003; Gerhardt and Hoffman, 2001; Oldenziel et al., 2006). A layer of Nafion ${ }^{\circledR}$ alone over CAT yielded a high sensitivity $\mathrm{H}_{2} \mathrm{O}_{2}$ biosensor (design 4, $0.31 \pm 0.04 \mathrm{nA} / \mu \mathrm{M}, n=4)$, while a layer of Nafion ${ }^{\circledR}$ and PPDBSA over CAT (design 5) yielded a biosensor with no significant $\mathrm{H}_{2} \mathrm{O}_{2}$ response ( $p=0.4, n=3$ unpaired $t$-test).

Based on the high $\mathrm{H}_{2} \mathrm{O}_{2}$ sensitivity of design 3, Nafion ${ }^{\circledR}$ and PPD layers were placed under the CAT layer, and
CAT was immobilized by cross-linking with GA (design 6). Design 6 yielded a high and reproducible $\mathrm{H}_{2} \mathrm{O}_{2}$ sensitivity $(0.45 \pm 0.03 \mathrm{nA} / \mu \mathrm{M}, n=8)$. Also, the CAT, BLANK and BLANK-CAT electrode responses were linear $\left(R^{2}=0.9999\right)$, indicating that $C_{\mathrm{HP}}$ is constant over the concentrations of $\mathrm{H}_{2} \mathrm{O}_{2}$ tested here. Due to the success of design 6, different methods for immobilizing the CAT layer on Naf/PPD were also tested. Immobilizing the CAT layer with GA-BSA (design 7), cellulose acetate (CA, design 8) and polystyrene (Sty, design 9) all resulted in lower $\mathrm{H}_{2} \mathrm{O}_{2}$ sensitivities than immobilization with GA: $0.12 \pm 0.02(n=4) ; 0.09 \pm 0.03(n=4) ;$ and $0.16 \pm 0.04$ $(n=3) \mathrm{nA} / \mu \mathrm{M}$, respectively. The reduced sensitivity could be due to lower permeability of the outer layer to $\mathrm{H}_{2} \mathrm{O}_{2}$ or denaturation of a portion of the CAT enzyme during application of the outer layer. For designs 7 and 8 , the $\mathrm{H}_{2} \mathrm{O}_{2}$ response at the blank electrode is less than for design 6 (Fig. 1A), indicating that $\mathrm{H}_{2} \mathrm{O}_{2}$ permeability contributes to the lowered sensitivity. Reduced CAT activity may also play a role. In contrast, the $\mathrm{H}_{2} \mathrm{O}_{2}$ permeability for the blanks of designs 6 and 9 is comparable, indicating that reduced CAT activity is the most likely cause of the reduced sensitivity.

\subsection{Ascorbic acid interference rejection}

Like $\mathrm{H}_{2} \mathrm{O}_{2}$, AA is also oxidized efficiently at $+700 \mathrm{mV}$ on the Pt surface (Lowry and O'Neill, 1994), and resulting currents could interfere with the measurement of $\mathrm{H}_{2} \mathrm{O}_{2}$ in environments where AA is present, such as brain ECF in vivo. AA can be excluded from the surface of the electrode by polymers such as PPD and Nafion ${ }^{\circledR}$, and by lipids such as PEA. The ability of the designs with high $\mathrm{H}_{2} \mathrm{O}_{2}$ sensitivities (1, 2, 3, 4, and 6) to exclude AA from the electrode surface was therefore tested. Currents resulting from AA additions $(0.2-1.0 \mathrm{mM})$ were measured, and showed the characteristic low "self-blocking" plateau response associated with permselective layers based on PPD (Craig and O'Neill, 2003; Lowry and O'Neill, 1994) (Fig. 2B). The current at $1 \mathrm{mM}\left(I_{\mathrm{L}}\right)$ for each design is shown in Fig. 2A. For comparison, the current generated by $1 \mathrm{mM}$ AA on bare Pt was $1320 \pm 12$ $\mathrm{nA}(n=4)$. 

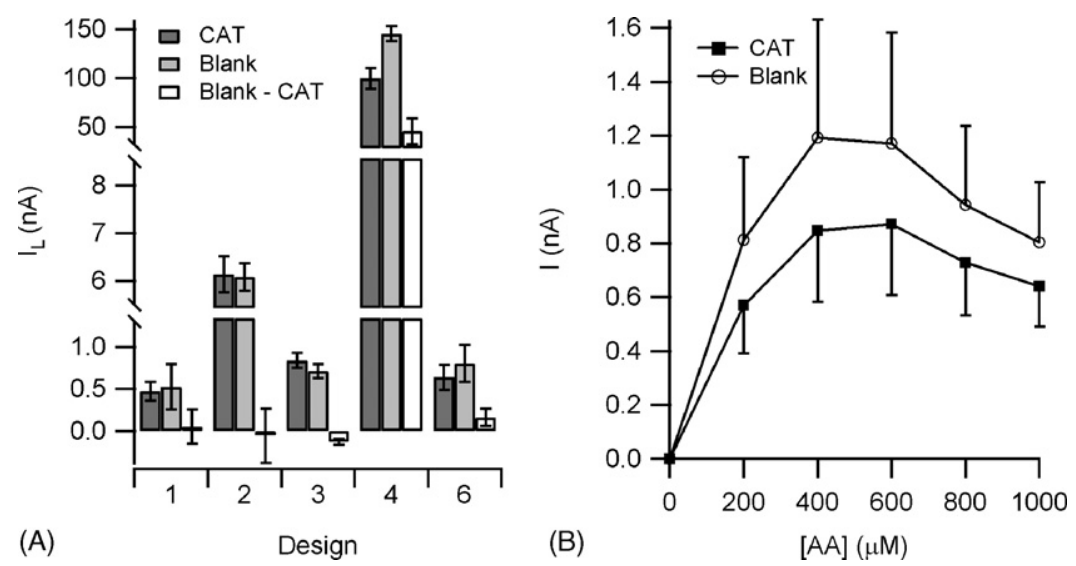

Fig. 2. Comparison of AA response for electrode designs 1, 2, 3, 4 and 6. AA calibrations $(0-1000 \mu \mathrm{M})$ were performed as described in Section 2. (A) The current at $1000 \mu \mathrm{M} \mathrm{AA}\left(I_{\mathrm{L}}\right)$ was determined for the CAT and blank electrodes. The AA response of the biosensor couple was determined by subtracting the CAT electrode current from the blank electrode current for each pair of electrodes. (B) The non-linear AA response of design 6 (Pt/Naf/PPD/CAT/GA and Pt/Naf/PPD/GA) as a function of AA concentration. All currents are mean \pm S.E.M.

All designs tested significantly reduced the $I_{\mathrm{L}}$ response compared with bare Pt, but to varying degrees. Designs 2 and 4 were the least effective, and blocked 99.5 and $89.0 \%$ of the AA current at $1 \mathrm{mM}$, respectively. While design 2 yielded a high $\mathrm{H}_{2} \mathrm{O}_{2}$ sensitivity (Fig. 1), the AA response was higher than designs 1,3 and 6 . The elevated AA response may be due to electrostatic attraction between the cationic PEI/PPD polymer layer and anionic AA. Alternatively, PEI may interfere with formation of the PPD polymer, reducing the ability of the polymer to exclude AA. Design 4 gave the highest AA response of all designs tested, demonstrating that Nafion ${ }^{\circledR}$ alone does not give as good an AA blockade as when combined with PPD. Due to their elevated AA responses relative to other designs tested here, designs 2 and 4 are poor candidates for in vivo implantation.

Designs 1, 3 and 6 blocked more than $99.95 \%$ of the AA current. The $I_{\mathrm{L}}$ values (nA) for the blank/CAT electrode pairs were as follows. design $1(n=6), 0.23 \pm 0.25$ versus $0.47 \pm 0.11$ $(p>0.40)$; design $3(n=3), 0.71 \pm 0.08$ versus $0.84 \pm 0.09$ $(p>0.34)$; and design $6(n=8), 0.80 \pm 0.22$ versus $0.64 \pm 0.15$ $(p>0.55)$. Thus, not only did these designs exclude AA effectively, but also gave well-matched interference rejection at the CAT and blank versions of the electrodes (Eq. (4)).

As mentioned previously, PPD is permeable to $\mathrm{H}_{2} \mathrm{O}_{2}$ but efficiently rejects AA (Craig and O'Neill, 2003; Hamdi et al., 2005; Lowry et al., 1994; McMahon et al., 2004; Murphy, 1998; Sasso et al., 1990). PEA was used here as inclusion of a PEA layer underneath PPD has been shown to increase rejection of interference species (McAteer and O'Neill, 1996; Wang and Wu, 1993). It is shown here that there was no significant difference between the AA response of designs 3, with a PEA layer, and design 6, with a Nafion ${ }^{\circledR}$ layer (Fig. 2). Thus, Nafion ${ }^{\circledR}$ is as effective as PEA in reducing the AA response when combined with PPD and layered under the enzyme. Inclusion of BSA in the PPD polymer has also been shown to improve AA interference blockade (McAteer and O'Neill, 1996). However, Nafion ${ }^{\circledR} / \mathrm{PPD}$ is as effective at rejecting AA as PEA/PPD-BSA.

As demonstrated in Eqs. (1)-(4), the closer $C_{\text {INT }}$ is to unity (i.e., the more similar the CAT and blank electrode response to AA and other endogenous interference species), the more accurate the measurement of $\mathrm{H}_{2} \mathrm{O}_{2}$ concentration. The small difference between the CAT and blank electrodes AA responses seems to arise due to trace metal contamination of the buffer. Reaction (5), which is catalyzed by heavy metals such as $\mathrm{Fe}^{3+}$ and $\mathrm{Cu}^{2+}$, produces $\mathrm{H}_{2} \mathrm{O}_{2}$ (Taqui and Martell, 1967), which is then oxidized at the electrode surface.

$\mathrm{O}_{2}+\mathrm{AA} \rightarrow \mathrm{H}_{2} \mathrm{O}_{2}+$ dehydroascorbate

Hence, the CAT electrode current is lower than the blank electrode current because some of the $\mathrm{H}_{2} \mathrm{O}_{2}$ produced by reaction (5) is degraded before reaching the electrode surface. Several experiments have been done to confirm this (data not shown). The AA response at both electrodes was higher in air-saturated PBS than in nitrogen-saturated PBS. Addition of desferral, an iron chelator, into the PBS reduced the AA response at both electrodes. Also, addition of catalase to the PBS reduced the AA response further, compared to experiments carried out in nitrogen-saturated PBS or in the presence of desferral. Finally, the difference between the AA response at the CAT and blank electrodes was further decreased when catalase was present in the PBS.

As for $\mathrm{H}_{2} \mathrm{O}_{2}$, the bare Pt electrode response to AA is linear with concentration. This linearity was not observed after modification of the bare Pt electrodes (Fig. 2B). The AA response at both CAT and blank electrodes increased at concentrations up to $400 \mu \mathrm{M}$ AA, and then decreases slightly at higher AA concentrations. Thus, the biosensor response to AA concentrations over a wide range $(0.2-1.0 \mathrm{mM})$ is relatively constant. This is important as the extracellular AA concentration can fluctuate widely in vivo. For example, AA concentrations in the striatum can double during intense motor activity (Fillenz et al., 1986).

\subsection{Hydrogen peroxide sensitivity in the presence of ascorbic acid}

The basal concentration of AA in vivo is $\sim 400 \mu \mathrm{M}$ (Miele and Fillenz, 1996). To mimic the in vivo environment, $\mathrm{H}_{2} \mathrm{O}_{2}$ 

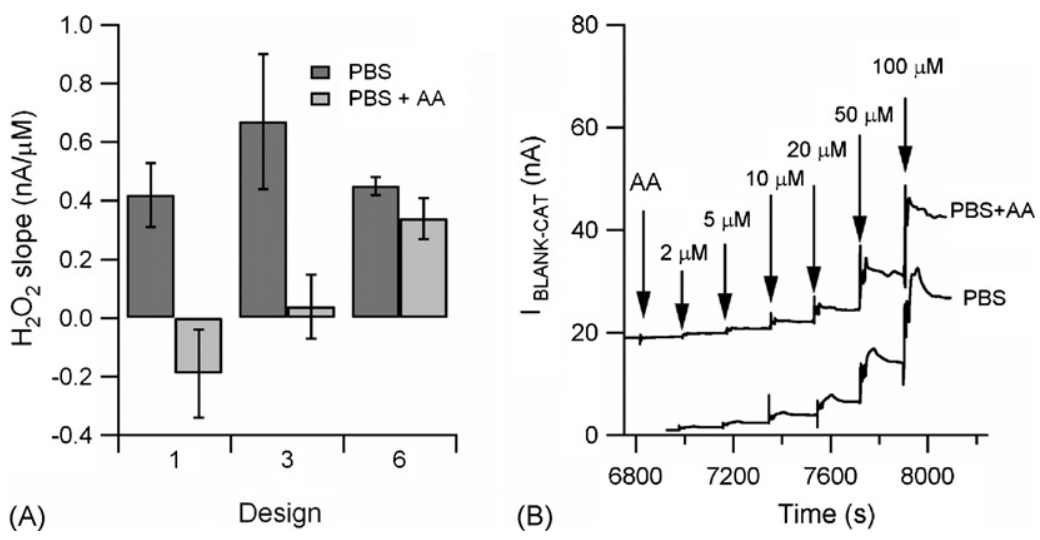

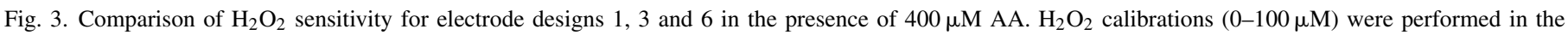

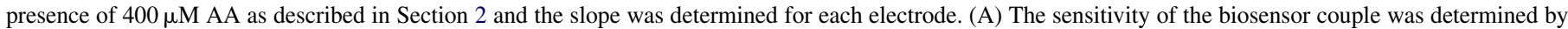

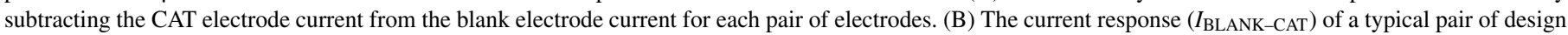
6 (Pt/Naf/PPDGA-Pt/Naf/PPD/CAT/GA) electrodes during $\mathrm{H}_{2} \mathrm{O}_{2}$ calibration in PBS and PBS $+400 \mu \mathrm{M}$ AA. Traces have been offset for clarity.

calibrations were repeated in the presence of $400 \mu \mathrm{M}$ AA (Fig. 3) for the designs with the lowest AA responses (designs 1, 3 and 6). This comparison is also important because AA has been shown previously to inhibit catalase under certain conditions (Davison et al., 1986).

Only design 6 retained $\mathrm{H}_{2} \mathrm{O}_{2}$ sensitivity in AA solutions comparable to that in the absence of AA. The BSA present in both designs 1 and 3 may be involved in the interaction of $\mathrm{H}_{2} \mathrm{O}_{2}$ and AA (Satoh et al., 1997). The sensitivity of design 6 was slightly less in the presence of $400 \mu \mathrm{M}$ AA $(\sim 20 \%)$ than in PBS alone, but the difference was not significant $(p>0.8$, paired $t$-test, $n=6$ ). This modest decrease in the $\mathrm{H}_{2} \mathrm{O}_{2}$ signal caused by large excesses of AA is similar to that reported for redox hydrogel-based biosensors (Mitala and Michael, 2006; Oldenziel et al., 2006). Since it is not possible at present to determine absolute ECF levels of an analyte using in situ electrochemical techniques, these sensors are designed to monitor continuous changes in $\mathrm{H}_{2} \mathrm{O}_{2}$ concentrations. So little is known about ECF $\mathrm{H}_{2} \mathrm{O}_{2}$ dynamics, that determining which conditions cause a relative increase or decrease of $\mathrm{H}_{2} \mathrm{O}_{2}$ in the brain would be a significant advance. Therefore, of the designs tested here, design 6 is the best candidate for in vivo implantation.

\subsection{Interference rejection}

Ascorbic acid is the major source of electrochemical interference in brain ECF due to its high concentration. However, there are other electroactive species present that can also be oxidized at $+700 \mathrm{mV}$. Therefore, the ability of the most successful design (design 6) to exclude other interference species commonly found in ECF from the electrode surface was determined. The interference species tested were: L-tyrosine, DOPAC, 5-HIAA, L-tryptophan, dopamine, glutathione, L-cysteine, serotonin, homovanillic acid and uric acid. Currents from these interference species were measured over concentration ranges expected to be observed in vivo in brain ECF (Table 2). For comparison, the difference between the blank and CAT electrode for $2 \mu \mathrm{M} \mathrm{H}_{2} \mathrm{O}_{2}$ is also shown. There was no statistically significant difference between the blank and CAT electrodes for any of the interference species tested ( $p>0.2$, unpaired $t$-test). More importantly, the differences were small compared to the

Table 2

Response of design 6 (Pt/Naf/PPD/CAT/GA, Pt/Naf/PPD/GA) to various interference species found in vivo

\begin{tabular}{|c|c|c|c|c|}
\hline & Blank (nA/ $\mu \mathrm{M}, \pm$ S.E.M., $n=4)$ & CAT (nA/ $\mu \mathrm{M}, \pm$ S.E.M., $n=4)$ & $\mathrm{ECF}(\mu \mathrm{M})$ & Blank-CAT (nA, \pm S.E.M., $n=4)^{\mathrm{a}}$ \\
\hline Glutathione & $0.0003 \pm 0.0001$ & $0.0002 \pm 0.0001$ & $50^{\mathrm{b}}$ & $0.003 \pm 0.003$ \\
\hline 5-HIAA & $0.0050 \pm 0.0013$ & $0.0003 \pm 0.0009$ & $10^{\mathrm{c}}$ & $-0.003 \pm 0.010$ \\
\hline HVA & $0.0010 \pm 0.0001$ & $0.0012 \pm 0.0002$ & $20^{\mathrm{c}}$ & $-0.004 \pm 0.004$ \\
\hline $\mathrm{AA}$ & $0.0011 \pm 0.0003^{\mathrm{d}}$ & $0.0007 \pm 0.0002^{\mathrm{d}}$ & $400^{c}$ & $0.14 \pm 0.13$ \\
\hline UA & $0.0018 \pm 0.0001$ & $0.0022 \pm 0.0003$ & $100^{c}$ & $-0.036 \pm 0.031$ \\
\hline L-Tyrosine & $0.0019 \pm 0.0001$ & $0.0020 \pm 0.0002$ & $100^{\mathrm{b}}$ & $-0.006 \pm 0.029$ \\
\hline DOPAC & $0.0019 \pm 0.0002$ & $0.0016 \pm 0.0002$ & $20^{\mathrm{c}}$ & $0.005 \pm 0.005$ \\
\hline L-Tryptophan & $0.0029 \pm 0.0005$ & $0.0026 \pm 0.0004$ & $100^{\mathrm{b}}$ & $0.028 \pm 0.067$ \\
\hline L-Cysteine & $0.0090 \pm 0.0004$ & $0.010 \pm 0.002$ & $50^{\mathrm{b}}$ & $-0.059 \pm 0.10$ \\
\hline DA & $0.20 \pm 0.04$ & $0.26 \pm 0.05$ & $0.05^{\mathrm{c}}$ & $-0.003 \pm 0.003$ \\
\hline 5-HT & $0.60 \pm 0.21$ & $0.70 \pm 0.29$ & $0.01^{\mathrm{c}}$ & $-0.002 \pm 0.007$ \\
\hline $\mathrm{H}_{2} \mathrm{O}_{2}$ & $0.73 \pm 0.06$ & $0.30 \pm 0.05$ & 2 & $0.87 \pm 0.13$ \\
\hline
\end{tabular}

\footnotetext{
a Expected current in vivo at the estimated ECF concentrations given in column 4

b ECF concentrations not known, high $\mu \mathrm{M}$ values chosen.

c (Lowry and O’Neill, 2006).

d $n=9$.
} 
response for $2 \mu \mathrm{M} \mathrm{H}_{2} \mathrm{O}_{2}$. Therefore, micromolar concentrations of $\mathrm{H}_{2} \mathrm{O}_{2}$ can be reliably measured in the presence of these interference species, as the difference between the CAT and blank electrode for $\mathrm{H}_{2} \mathrm{O}_{2}$ was vastly larger than the difference for any interference species.

\section{Conclusions}

A number of $\mathrm{H}_{2} \mathrm{O}_{2}$ biosensors were tested in vitro, based on a novel dual-probe catalase design. The best design was $\mathrm{Pt} / \mathrm{Nafion} / \mathrm{PPD} / \mathrm{CAT} / \mathrm{GA}$. Of the designs tested here, this design gave one of the highest $\mathrm{H}_{2} \mathrm{O}_{2}$ sensitivities that were not significantly affected by the presence of $0.4 \mathrm{mM}$ AA. The response of the biosensor was $\sim 0.1 \%$ that for bare Pt at $1 \mathrm{mM} \mathrm{AA}$, and showed a plateau in the range of AA concentration relevant to brain ECF. As the biosensor is composed of a CAT and blank electrode, the small contributions of interference species can be subtracted out if the response is the same at both electrodes, which was shown to be the case for the main interference species present in brain ECF. Therefore, the Pt/Nafion/PPD/CAT/GA design described here is a promising biosensor for in vivo monitoring of endogenous $\mathrm{H}_{2} \mathrm{O}_{2}$ in brain ECF. The stability of the biosensor in vitro and its characterization in vivo is underway.

\section{Acknowledgements}

We gratefully acknowledge the Health Research Board, Ireland (RP/2004/44) and Science Foundation Ireland (04/BR/C0198) for financial support.

\section{References}

Avshalumov, M.V., Chen, B.T., Koos, T., Tepper, J.M., Rice, M.E., 2005. J. Neurosci. 25 (17), 4222-4231.

Avshalumov, M.V., Chen, B.T., Marshall, S.P., Pena, D.M., Rice, M.E., 2003. J. Neurosci. 23 (7), 2744-2750.

Avshalumov, M.V., Chen, B.T., Rice, M.E., 2000. Brain Res. 882 (1-2), 86-94. Avshalumov, M.V., Rice, M.E., 2002. J. Neurophysiol. 87 (6), 2896-2903.

Avshalumov, M.V., Rice, M.E., 2003. Proc. Natl. Acad. Sci. U.S.A. 100 (20), $11729-11734$.

Bao, L., Avshalumov, M.V., Rice, M.E., 2005. J. Neurosci. 25 (43), 10029-10040.

Belay, A., Collins, A., Ruzgas, T., Kissinger, P.T., Gorton, L., Csoregi, E., 1999. J. Pharm. Biomed. Anal. 19 (1-2), 93-105.

Brown, F.O., Lowry, J.P., 2003. Analyst 128 (6), 700-705.

Chen, B.T., Avshalumov, M.V., Rice, M.E., 2001. J. Neurophysiol. 85 (6), 2468-2476.

Chen, B.T., Avshalumov, M.V., Rice, M.E., 2002. J. Neurophysiol. 87 (2), $1155-1158$.

Craig, J.D., O’Neill, R.D., 2003. Analyst 128 (7), 905-911.

Davison, A.J., Kettle, A.J., Fatur, D.J., 1986. J. Biol. Chem. 261 (3), 1193-1200.

Dixon, B.M., Lowry, J.P., O’Neill, R.D., 2002. J. Neurosci. Methods 119 (2), $135-142$.
Ferapontova, E.E., Grigorenko, V.G., Egorov, A.M., Borchers, T., Ruzgas, T., Gorton, L., 2001. Biosens. Bioelectron. 16 (3), 147-157.

Fillenz, M., MacDonald, I.A., Marsden, C.A. (Eds.), 1986. Monitoring Neurotransmitter Release During Behaviour. Chichester, U.K..

Friedemann, M.N., Robinson, S.W., Gerhardt, G.A., 1996. Anal. Chem. 68 (15), 2621-2628.

Gerhardt, G.A., Hoffman, A.F., 2001. J. Neurosci. Methods 109 (1), 13-21.

Hamdi, N., Wang, J.J., Monbouquette, H.G., 2005. J. Electroanal. Chem. 581 (2), 258-264.

Hyslop, P.A., Zhang, Z., Pearson, D.V., Phebus, L.A., 1995. Brain Res. 671 (2), $181-186$.

Kulagina, N.V., Michael, A.C., 2003. Anal. Chem. 75 (18), 4875-4881.

Lei, B., Adachi, N., Arai, T., 1997a. Neurosci. Lett. 222 (2), 91-94.

Lei, B., Adachi, N., Arai, T., 1998. Brain Res. Brain Res. Protoc. 3 (1), 33-36.

Lei, B., Adachi, N., Nagaro, T., Arai, T., 1997b. Brain Res. 764 (1-2), 299-302.

Lowry, J.P., McAteer, K., El Atrash, S.S., Duff, A., O’Neill, R.D., 1994. Anal. Chem. 66 (10), 1754-1761.

Lowry, J.P., Miele, M., O’Neill, R.D., Boutelle, M.G., Fillenz, M., 1998a. J. Neurosci. Methods 79 (1), 65-74.

Lowry, J.P., O’Neill, R.D., 2006. In: Grimes, C.A., Dickey, E.C., Pishko, M.V. (Eds.), Encyclopedia of Sensors. California, pp. 1-23.

Lowry, J.P., O’Neill, R.D., 1994. Electroanalysis 6 (5-6), 369-379.

Lowry, J.P., O'Neill, R.D., Boutelle, M.G., Fillenz, M., 1998b. J. Neurochem. 70 (1), 391-396.

Lowry, J.P., Ryan, M.R., O’Neill, R.D., 2001. In: OÇonnor, W.T., LOwry, J.P., OÇonnor, J.J., O'Neill, R.D. (Eds.), Monitoring Molecules in Neuroscience. Dublin, Ireland, pp. 70-71.

Mao, L., Osborne, P.G., Yamamoto, K., Kato, T., 2002. Anal. Chem. 74 (15), 3684-3689.

McAteer, K., O'Neill, R.D., 1996. Analyst 121 (6), 773-777.

McMahon, C.P., Killoran, S.J., Kirwan, S.M., O’Neill, R.D., 2004. J. Chem. Soc. Chem. Commun. 18, 2128-2130.

McMahon, C.P., Rocchitta, G., Serra, P.A., Kirwan, S.M., Lowry, J.P., O’Neill, R.D., 2006. Analyst 131 (1), 68-72.

Miele, M., Fillenz, M., 1996. J. Neurosci. Methods 70 (1), 15-19.

Mitala, J.J., Michael, A.C., 2006. Anal. Chim. Acta 556 (2), 326-332.

Murphy, L.J., 1998. Anal. Chem. 70 (14), 2928-2935.

Oldenziel, W.H., Dijkstra, G., Cremers, T.I.F.H., Westerink, B.H.C., 2006. Anal. Chem. 78 (10), 3366-3378.

O’Neill, R.D., Lowry, J.P., Mas, M., 1998. Crit. Rev. Neurobiol. 12 (1-2), 69-127.

Ryan, M.R., Lowry, J.P., O’Neill, R.D., 1997. Analyst 122 (11), 1419-1424.

Saraceno, R.A., Ewing, A.G., 1988. J. Electroanal. Chem. 257 (1-2), 83-93.

Sasso, S.V., Pierce, R.J., Walla, R., Yacynych, A.M., 1990. Anal. Chem. 62 (11), 1111-1117.

Satoh, K., Ida, Y., Kimura, S., Taguchi, K., Numaguchi, M., Gomi, K., Kochi, M., Sakagami, H., 1997. Anticancer Res. 17 (6), 4377-4380.

Schuvailo, O.N., Dzyadevych, S.V., El'skaya, A., Gautier-Sauvigne, S., Csoregi, E., Cespuglio, R., Soldatkin, A.P., 2005. Biosens. Bioelectron. 21 (1), 87 94.

Simonian, N.A., Coyle, J.T., 1996. Annu. Rev. Pharmacol. Toxicol. 36, 83106.

Stone, J.R., Yang, S.P., 2006. Antioxidants Redox Signaling 8 (3-4), 243-270.

Taqui, K., Martell, A.E., 1967. J. Am. Chem. Soc. 89 (16), 4176-4185.

Varma, S., Yigzaw, Y., Gorton, L., 2006. Anal. Chim. Acta 556 (2), 319-325.

Wang, G., Xu, J.J., Chen, H.Y., Lu, Z.H., 2003. Biosens. Bioelectron. 18 (4), 335-343.

Wang, J., Wu, H., 1993. Anal. Chim. Acta 283 (2), 683-688.

Wilson, G.S., Gifford, R., 2005. Biosens. Bioelectron. 20 (12), 2388-2403. 